\title{
Time delays in each step from symptom onset to treatment in acute myocardial infarction: Results from a nation-wide TURKMI registry
}

\author{
Mustafa Kemal Erol1, (D), Meral Kayıkçığlı², (D, Mustafa Kılıçkap³, (D), Arda Gülert (iD, Önder Öztürk5 (D),

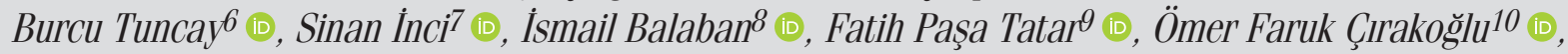 \\ Emine Gazi ${ }^{11}$ (D), Eftal Murat Bakırcı ${ }^{12}$ (1), Cağrı Yayla13 (1), Mehmet Ali Astarcıoğlu14 (1), \\ Bilge Duran Karaduman ${ }^{15}$ (i), Ekrem Aksu ${ }^{16}$ (i), Yakup Alsancak17 (iD, Nadir Emlek ${ }^{18}$ (D), \\ Mustafa Kürşat Tigen 19 (D), Nihan Turhan Çağlar20 (D), Ramazan Düz ${ }^{21}$ (D), Mehmet Inanır22 (D), \\ Öner Özdoğan²3 (), Oğuz Yavuzgil2 (iD, on behalf of TURKMI Study Group
}

\author{
${ }^{1}$ Department of Cardiology, Şişli International Kolan Hospital; İstanbul-Turkey \\ ${ }^{2}$ Department of Cardiology, Faculty of Medicine, Ege University; İzmir-Turkey \\ ${ }^{3}$ Department of Cardiology, Faculty of Medicine, Ankara University; Ankara-Turkey \\ ${ }^{4}$ Department of Cardiology, Health Science University, İstanbul Mehmet Akif Ersoy Thoracic and Cardiovascular Surgery Training and \\ Research Hospital; İstanbul-Turkey \\ ${ }^{5}$ Department of Cardiology, Health Science University, Gazi Yaşargil Training and Research Hospital; Diyarbakır-Turkey \\ ${ }^{6}$ Department of Cardiology, Health Science University, Bursa Yüksek İhtisas Training and Research Hospital; Bursa-Turkey \\ ${ }^{7}$ Department of Cardiology, Faculty of Medicine, Aksaray University; Aksaray-Turkey \\ ${ }^{8}$ Department of Cardiology, Health Science University, Kartal Koşuyolu Yüksek İhtisas Training and Research Hospital; İstanbul-Turkey \\ ${ }^{9}$ Department of Cardiology, Faculty of Medicine, Bülent Ecevit University; Zonguldak-Turkey \\ ${ }^{10}$ Department of Cardiology, Health Science University, Ahi Evran Thoracic and Cardiovascular Surgery \\ Training and Research Hospital; Trabzon-Turkey \\ ${ }^{11}$ Department of Cardiology, Faculty of Medicine, Onsekiz Mart University; Çanakkale-Turkey \\ ${ }^{12}$ Department of Cardiology, Faculty of Medicine, Erzincan Binali Yıldırım University; Erzincan-Turkey \\ ${ }^{13}$ Department of Cardiology, Health Science University, Türkiye Yüksek İhtisas Training and Research Hospital; Ankara-Turkey \\ ${ }^{14}$ Department of Cardiology, Dumlupınar University, Evliya Çelebi Training and Research Hospital; Kütahya-Turkey \\ ${ }^{15}$ Department of Cardiology, Yıldırım Beyazit University, Atatürk Training and Research Hospital; Ankara-Turkey \\ ${ }^{16}$ Department of Cardiology, Faculty of Medicine, Sütçü İmam University; Kahramanmaras-Turkey \\ ${ }^{17}$ Department of Cardiology, Faculty of Medicine, Necmettin Erbakan University; Konya-Turkey \\ ${ }^{18}$ Department of Cardiology, Faculty of Medicine, Recep Tayyip Erdoğan University; Rize-Turkey \\ ${ }^{19}$ Department of Cardiology, Faculty of Medicine, Marmara University; İstanbul-Turkey \\ 20Department of Cardiology, Health Science University, Bakırköy Dr. Sadi Konuk Training and Research Hospital; İstanbul-Turkey \\ ${ }^{21}$ Department of Cardiology, Health Science University, Van Training and Research Hospital; Van-Turkey \\ 22Department of Cardiology, Faculty of Medicine, Abant İzet Baysal University; Bolu-Turkey \\ ${ }^{23}$ Department of Cardiology, Health Science University, Tepecik Training and Research Hospital; İzmir-Turkey
}

Cite this article as: Erol MK, Kayıkçığlu M, Kılıçkap M, Güler A, Öztürk Ö, Tuncay B, et al. Time delays in each step from symptom onset to treatment in acute myocardial infarction: Results from a nation-wide TURKMI registry. Anatol J Cardiol 2021; 25: 294-303. 
Objective: In this study, we aimed to analyze the TURKMI registry to identify the factors associated with delays from symptom onset to treatment that would be the focus of improvement efforts in patients with acute myocardial infarction (AMI) in Turkey.

Methods: The TURKMI study is a nation-wide registry that was conducted in 50 centers capable of 24/7 primary percutaneous coronary intervention (PCI). All consecutive patients ( $n=1930)$ with AMI admitted to coronary care units within 48 hours of symptom onset were prospectively enrolled during a predefined 2-week period between November 1, 2018, and November 16, 2018. All the patients were examined in detail with regard to the time elapsed at each step from symptom onset to initiation of treatment, including door-to-balloon time (D2B) and total ischemic time (TIT).

Results: After excluding patients who suffered an AMI within the hospital (2.6\%), the analysis was conducted for 1879 patients. Most of the patients $(49.5 \%)$ arrived by self-transport, $11.8 \%$ by emergency medical service (EMS) ambulance, and $38.6 \%$ were transferred from another EMS without PCI capability. The median time delay from symptom-onset to EMS call was $52.5(15-180)$ min and from EMS call to EMS arrival 15 (10-20) min. In ST-segment elevation myocardial infarction (STEMI), the median D2B time was 36.5 (25-63) min, and median TIT was 195 (115330) min. TIT was significantly prolonged from 151 (90-285) min to 250 (165-372) min in patients transferred from non-PCI centers. The major significant factors associated with time delay were patient-related delay and the mode of hospital arrival, both in STEMI and non-STEMI.

Conclusion: The baseline evaluation of the TURKMI study revealed that an important proportion of patients presenting with AMI within 48 hours of symptom onset reach the PCI treatment center later than the time proposed in the guidelines, and the use of EMS for admission to hospital is extremely low in Turkey. Patient-related factors and the mode of hospital admission were the major factors associated with the time delay to treatment.

Keywords: myocardial infarction, ambulance, total ischemic time, treatment delay, door to balloon time

\section{Introduction}

In patients with acute myocardial infarction (AMI), mortality can be minimized only by rapid diagnosis and early treatment. The treatment guidelines developed as a result of numerous randomized controlled studies emphasize the importance of restoration of blood supply to the occluded vessel as early as possible in patients with ST-segment elevation myocardial infarction (STEMI) (1, 2). One of the key aspects of myocardial salvage is to shorten the duration of total ischemia in primary percutaneous coronary interventions (PCI). Any delay from symptom onset to treatment is associated with an increase in microvascular obstruction, which further increases the infarct size and mortality $(3,4)$. In addition, time frames in the management of patients with non-ST segment elevation myocardial infarction (NSTEMI) have been described according to their risk categories (2). AMI treatment strategies and logistic details, including the use of emergency medical service (EMS), may also affect the time delays from symptom onset to treatment. Therefore, knowing the factors affecting time delays can provide information about which areas to focus on at the country level. In this study, we aimed to identify the factors associated with delays from symptom onset to treatment that would be the focus of improvement efforts in patients with AMI using the data of national AMI registry in Turkey (TURKMI).

\section{Methods}

TURKMI (clinicaltrials.gov NCT04241770) is a 15-day snapshot registry that enrolled all consecutive patients with acute MI in Turkey. The rationale and design of the TURKMI registry have been described in detail previously $(5,6)$. All the patients were prospectively enrolled between November 01 and November 15, 2018, from 50 cardiology clinics representing the 12 EurostatNuts Statistical Regions of Turkey proportional to Turkey's 2018 census (7). All the centers were capable of 24/7 service for primary $\mathrm{PCl}$. The study protocol was reviewed and approved by the Ethics Committee of University of Health Sciences, Istanbul Mehmet Akif Ersoy Thoracic and Cardiovascular Surgery Training and Research Hospital (No: 2018-46 and Date: 09/10/2018). Written informed consent was obtained from all the participants.

Diagnosis of $\mathrm{Ml}$ was based on the third universal definition of MI (8), and the details are given elsewhere $(5,6)$. Men and women aged $\geq 18$ years were prospectively enrolled if they fulfilled the following inclusion criteria: (1) were hospitalized within 48 hours of the onset of symptoms of the index event, (2) had a final (discharge) diagnosis of acute MI, either STEMI or NSTEMI, with positive troponin levels, and (3) had signed an informed consent. Patients unwilling or unable to consent were excluded. For this analysis, patients who had had an AMI in the other wards (in-hospital AMI, n=51) of the study centers were excluded.

The study population received routine clinical assessment with standard medical care currently performed in routine clinical practice. According to the TURKMI protocol, prescriptions of drugs and indications of diagnostic/therapeutic procedures were left to the participating cardiologists to decide (5). As this was an observational protocol, the patients did not receive any experimental intervention or treatment as a consequence of their participation.

All the patients were examined in detail with regard to the time elapsed at each step from symptom onset to initiation of treatment. The recorded timings were symptom onset time, prehospital EMS calling time, time taken by EMS to reach the patients, time of admission to hospital, and time of first coronary treatment initiation (first balloon inflation). Time delays were calculated from symptom onset to EMS call, from EMS arrival to hospital arrival, from symptom onset to hospital arrival, and time delay between the 2 hospitals. The door to balloon time (D2B) was calculated as the time elapsed from the arrival of a patient 


\section{HIGHLIGHTS}

- Time delays from symptom onset to treatment are extremely important in the management of AMI affecting the overall mortality and morbidity.

- $\quad$ TURKMI study revealed that an important proportion of patients presenting with $\mathrm{AMI}$ get $\mathrm{PCI}$ treatment later than the time proposed in the guidelines.

- The use of EMS for admission is extremely low in Turkey.

- Patient-related factors, that is, underuse of EMS and longer time from symptom to EMS call seem to be the major factors leading to the prolonged duration of ischemia (time to treatment) during the course of $\mathrm{AMI}$

with STEMI in the emergency room until the time that a balloon was inflated in the culprit coronary artery. Total ischemic time (TIT) was defined as the time from symptom onset to the first intracoronary therapy (first balloon inflation) for patients with STEMI. All time delays in patients with NSTEMI were also calculated with regard to the risk level classified in accordance with ESC guidelines (2).

The mode of hospital arrival including by self-transport, by ambulance, or by transfer from another hospital without primary $\mathrm{PCl}$ capability were also recorded in detail. Patients who were admitted to emergency departments by their own facilities without EMS were accepted as self-transported.

\section{Statistical analysis}

All analyses were performed using Statistical Package for Social Sciences (SPSS), version 18.0 for Windows (SPSS Inc., Chicago, USA) and $R$ software version 3.6.3 (R Foundation for Statistical Computing, Vienna, Austria), and a $p$ value of $<0.05$ was considered significant. Continuous variables were presented as mean \pm standard deviation or median (interquartile range) depending on whether they had normal distribution or not and compared using the $t$ test or Mann-Whitney $U$ test, where appropriate. Categorical variables were presented as frequency and percentage and compared using the Pearson chi-squared test or Fisher exact test. Linear regression analysis was used to determine the factors associated with the time delays and conducted for STEMI and NSTEMI separately. The dependent variable was the time from symptom onset to balloon inflation (TIT) for STEMI, and the time from symptom onset to hospital arrival for NSTEMI, as urgent reperfusion is not needed in all patients with NSTEMI in contrast to patients with STEMI. Patients diagnosed with $\mathrm{MI}$ during their hospitalization period for other reasons were excluded as the time variable did not represent the general population. Because of the violation of linear regression, logarithmic transformation was applied to dependent variables, and the log-transformed variables were used in the analyses. For ease of interpretation, regression analysis output was presented as "percent change in delay" in one category compared with the baseline category for categorical variables and per one unit change in independent continuous variables. The cities where the study centers were located were used as a cluster variable; therefore, clustered robust standard errors were calculated. Restricted cubic spline with 5 knots was used to assess the nonlinear relationship between the time variable and age. An age of 55 years was used as the reference point for analyzing the nonlinear relationship. Moreover, to compare the time delay between patients with STEMI and NSTEMI, log-transformed time from symptom-onset to hospital arrival was used as a dependent variable, and diagnosis (STEMI or NSTEMI) was modeled as an independent variable along with other independent variables, which included age, sex, history of coronary artery disease (CAD), hypertension, diabetes, family history of CAD, and arrival type (EMS use, self-transport, or transfer from another hospital). As more than one symptom might be present in a patient, the symptom was not included in the model because of the violation of the independence assumption.

\section{Results}

A total of 1930 patients with AMI [1195 (62\%) NSTEMI and $735(38 \%)$ STEMI] were recruited. The mean age was $62 \pm 13$ years, and $26.1 \%$ were women. Table 1 shows the baseline clinical characteristics of the study population. The depicted subgroups in Table 1 are patients with NSTEMI, STEMI, and patients with STEMI admitted within 12 hours of symptoms.

\section{Mode of hospital admission}

Evaluation of the mode of admission to the study cities revealed that only $11.8 \%$ arrived by EMS ambulance, $49.5 \%$ by self-transport, and $38.6 \%$ were transferred from another emergency cardiology/medical service without $\mathrm{PCl}$ facilities, and $2.6 \%$ of the patients were transferred from other wards in the same hospital or transferred because of postoperative myocardial infarction [39 patients $(3.3 \%)$ in the STEMI group and 12 patients $(1.6 \%)$ in the STEMI group].

When only the admissions to $\mathrm{PCl}$ capable hospitals are taken into consideration, only 222 of the 1153 patients (19.3\%) arrived at the emergency department by EMS ambulance (this proportion was $13 \%$ in NSTEMI and $29.7 \%$ in STEMI) and $80.7 \%$ by self-transport.

\section{Timings}

The timings at each period from symptom onset to treatment were calculated for 1879 patients after exclusion of patients with in-hospital MI. The median time delay between the onset of pain (symptom) and EMS call was 52.5 (15-180) min. This duration was significantly longer in patients with NSTEMI than in those with STEMI [77.5 (15-290) min vs. 32.5 (15-120), respectively, $p=0.024$ ] (Table 1). Median time delay between the EMS call and the arrival of EMS ambulance was 15 (10-20) min, and there was no significant time difference between patients with STEMI and those with NSTEMI. The median time from symptom onset to arrival at the hospital was $120(60-360) \mathrm{min}$. This time 


\begin{tabular}{|c|c|c|c|c|c|}
\hline & Total & NSTEMI & STEMI & $\begin{array}{c}\text { STEMI patients } \\
\text { admitted within } 12 \\
\text { hours of symptoms }\end{array}$ & $P$ value* \\
\hline $\mathrm{n}$ & 1930 & 1195 & 735 & 643 & - \\
\hline Age, years $($ mean $\pm S D)$ & $62 \pm 13$ & $63 \pm 13$ & $60 \pm 14$ & $60 \pm 14$ & $<0.001$ \\
\hline $\begin{array}{l}\text { History of CAD disease, (MI and/or CABG and/or } \\
\mathrm{PCI}) \mathrm{n}(\%)\end{array}$ & $550(28.5)$ & 418 (35) & $132(18)$ & $114(18.4)$ & $<0.001$ \\
\hline \multicolumn{6}{|l|}{ Mode of hospital admission, n (\%) } \\
\hline $\begin{array}{l}\text { Admission to Emergency Department directly (self- } \\
\text { transport) }\end{array}$ & $931(49.5)$ & $625(54.1)$ & $306(42.3)$ & $272(43.8)$ & \multirow[t]{2}{*}{$<0.001$} \\
\hline Other** & $51(2.6)$ & $39(3.3)$ & $12(1.6)$ & - & \\
\hline \multicolumn{6}{|l|}{ Time delays (min); Median (01-03) } \\
\hline From symptom onset to EMS call & $52.5(15-180)$ & $77.5(15-290)$ & $32.5(15-120)$ & $30(15-85)$ & 0.024 \\
\hline From EMS call to EMS arrival & $15(10-20)$ & $15(10-20)$ & $15(10-20)$ & $15(10-20)$ & 0.923 \\
\hline From EMS arrival to hospital arrival & $36(30-59)$ & $39.5(25-56.5)$ & $35(30-59)$ & $35(30-59)$ & 0.868 \\
\hline From symptom onset to hospital arrival & $120(60-360)$ & $165(60-420)$ & $90(45-220)$ & $78(40-175)$ & $<0.001$ \\
\hline $\begin{array}{l}\text { From the arrival to the first hospital to the second } \\
\text { hospital min }\end{array}$ & $172.5(99-300)$ & $237(121-390)$ & $120(64-180)$ & $119(60-180)$ & $<0.001$ \\
\hline Door-to-balloon time & - & - & $36(25-63)$ & $35(25-60)$ & - \\
\hline $\begin{array}{l}\text { *P value for comparison of all patients with STEMI and NSTEMI. } \\
\text { **Includes hospitalized patients in the index hospital for surgery } \\
\text { (Timings at each period from symptom onset to treatment were } c\end{array}$ & $\begin{array}{l}\text { ue for comparisor } \\
\text { her reasons } \\
\text { ated for } 1,879 \text { par }\end{array}$ & EMI patients the & itted within 48 & $\begin{array}{l}12 \text { hours of symptom } 0 \\
\text { MI - myocardial infar }\end{array}$ & $A B G$ - \\
\hline
\end{tabular}

gap was significantly longer in patients with NSTEMI than in those with STEMI [165 (60-420) min vs. 90 (45-220), respectively, $p=0.001]$. When transferred from centers without PCI capability, the patients lost a median time of 172.5 (99-300) min between hospitals. This time delay was significantly longer in patients with NSTEMI than in those with STEMI [237 (121-390) min vs. 120 (64-180), respectively, $p=0.001$ ) (Table 1).

In patients with STEMI, the median D2B time was 36 (25-63) min, and the median time delay between symptom onset and balloon inflation time (TIT) was 195 (115-330) min. The median TIT was significantly prolonged from $151(90-285) \mathrm{min}$ to 250 (165-372) min in patients transferred from non-PCl centers compared with those not transferred (Table 1).

In patients with STEMI who were admitted to the hospital within the first 12 hours of symptom onset, the median D2B time was $35(25-60) \mathrm{min}$, and the median time loss between symptom onset and balloon inflation, namely the TIT, was 185 (111-295) min (Table 1). The median TIT was significantly shorter in patients who underwent $\mathrm{PCl}$ in the first hospital compared with patients who were referred to a second hospital for PCI [141 (90-240) min vs. 243 (170-336), respectively, $p=0.001]$.

Coronary angiography was performed in $93.4 \%$ and $\mathrm{PCI}$ in $75 \%$ of the study population at index hospitalization. The proportions of coronary angiography and $\mathrm{PCI}$ were significantly higher in patients with STEMI vs. patients with NSTEMI $198.8 \%$ vs. $90.4 \%, p<0.001$; and $94.4 \%$ vs. $60.2 \%, p<0.001$, respectively). Fibrinolytic therapy was administered to only $13(1.8 \%)$ patients with STEMI.

In patients with STEMI who underwent primary PCI, TIT was less than 60 min in $5.7 \%$, less than 90 min in $18.1 \%$, and less than $120 \mathrm{~min}$ in $28.2 \%$ of the patients (Table 2). The median TITs from the onset of symptoms to balloon inflation were less than $60 \mathrm{~min}$ 


\begin{tabular}{|c|c|c|c|c|}
\hline & STEMI patients* & $\begin{array}{c}\text { Patients directly admitted } \\
\text { to a study center }\end{array}$ & $\begin{array}{l}\text { Patients transferred from } \\
\text { centers without PCI capability }\end{array}$ & $P$ value \\
\hline $\begin{array}{l}\text { Overall TIT (median (IQR) } \\
\text { (min-max) }\end{array}$ & $195(115-330)$ & $151(90-285)$ & $250(165-372)$ & $<0.001$ \\
\hline $\mathrm{TIT} \leq 120 \mathrm{~min}^{* *}$ & $178(28.2)$ & 146 (37.8) & $32(13.1)$ & $<0.001$ \\
\hline \multicolumn{5}{|c|}{$\begin{array}{l}\text { *In-hospital MIs were excluded. } \\
\text { **Guideline-recommended time. } \\
\text { For all analysis in this table, patients admitted to study centers from other wards in the same institution were excluded } \\
\text { TIT- total ischemic time, STEMI - ST elevation myocardial infarction. }\end{array}$} \\
\hline
\end{tabular}

Table 3. Proportion of patients who underwent coronary angiography and/or revascularization and time frames of revascularization in patients with NSTEMI

\begin{tabular}{|c|c|c|c|c|c|c|c|}
\hline & & Very-high risk & High risk & Moderate risk & Low risk & All & $P$ value \\
\hline$n(\%)$ & & $37(3.2)$ & $380(32.7)$ & $401(34.5)$ & $344(29.6)$ & 1162 & - \\
\hline Coronary angiography, n (\%) & & $34(91.9)$ & $337(88.7)$ & $354(88.3)$ & $325(94.5)$ & $1050(90.4)$ & 0.018 \\
\hline $\mathrm{PCI}[\mathrm{CAG}]^{*}, \mathrm{n}(\%)$ & & $27(79.4)$ & $229(68)$ & $229(64.7)$ & $214(65.8)$ & $699(66.6)$ & 0.328 \\
\hline \multirow{3}{*}{$\begin{array}{l}\text { Angiography time after hospital } \\
\text { arrival, } \mathrm{n}(\%)^{* *}\end{array}$} & $<2 \mathrm{~h}$ & $7(24.1)$ & $36(12.7)$ & 38 (13.2) & $35(13.6)$ & $116(13.5)$ & 0.395 \\
\hline & $<72 \mathrm{~h}$ & $28(96.6)$ & $268(94.7)$ & $265(92.0)$ & $242(94.2)$ & $803(93.7)$ & 0.501 \\
\hline & $\geq 72 \mathrm{~h}$ & $1(3.4)$ & $15(5.3)$ & $23(8.0)$ & $15(5.8)$ & $54(6.3)$ & 0.501 \\
\hline
\end{tabular}

in $8.5 \%$, less than 90 min in $25.4 \%$, and less than 120 min in $37.8 \%$ of patients who were initially admitted to a PCl-capable hospital. However, TIT was less than $60 \mathrm{~min}$ in $1.2 \%$, less than $90 \mathrm{~min}$ in $6.5 \%$, and less than $120 \mathrm{~min}$ in $13.1 \%$ of the patients transferred from non-PCl centers, thereby denoting an important time gap.

With regard to patients with NSTEMI, $29.6 \%$ were classified according to the ESC guideline criteria (8) as low risk, $34.5 \%$ as moderate risk, $32.7 \%$ as high risk, and $3.2 \%$ as very high risk on admission. Table 3 summarizes the frequencies of coronary angiography and/or revascularization and the time frames in patients with NSTEMI according to the risk categories. Among the patients with NSTEMI, coronary angiography was performed in $91.9 \%$ with very high risk, $88.7 \%$ with high risk, $88.3 \%$ with moderate risk, and $94.5 \%$ with low risk. Therefore, $90.4 \%$ of all patients with NSTEMI underwent coronary angiographic evaluation during the in-hospital period. PCI was performed in $62.2 \%$ of patients with low risk, $57.1 \%$ with moderate risk, $60.3 \%$ with high risk, and $73.0 \%$ with very high risk ( $p=0.195)$. Among patients with NSTEMI with very high-risk, only 7 (24.1\%) underwent coronary angiography within the guideline-recommended timeframe of $<2$ hours of admission. Meanwhile, only $64.7 \%$ of the patients with NSTEMI with high risk underwent coronary angiography within the first 24 hours of admission, and $92 \%$ of patients with moderate risk underwent coronary angiography within 72 hours of hospital admission.

Descriptive comparison revealed that the use of EMS ambulance in patients in TURKMI was not associated with age; sex; living in metropolitan municipalities; history of coronary artery disease (CAD), diabetes, or hypertension; and familial history of CAD (Table 4). As expected, only the admission symptoms of chest pain, syncope, or cardiac arrest were associated with increasing use of ambulance.

According to regression analysis, there was a nonlinear, significant relationship between age and time delay (TIT) in patients with STEMI $(p=0.006)$. The upper panel in Figure 1 shows a nearly flat line up to 50-55 years of age and then increases with age. There were no significant sex differences in terms of delay (Table 5). TIT tended to be lower $(8.5 \%)$ in patients with a history of CAD ( $p=0.077$ ). Although statistically nonsignificant, patients with diabetes mellitus had $4.7 \%$ increase in TIT compared with those without $(p=0.233)$, and patients with a family history of CAD had $5.5 \%$ lower TIT compared with those without $(p=0.190)$. The most important factor in TIT was the mode of arrival; patients who were transported from a center 


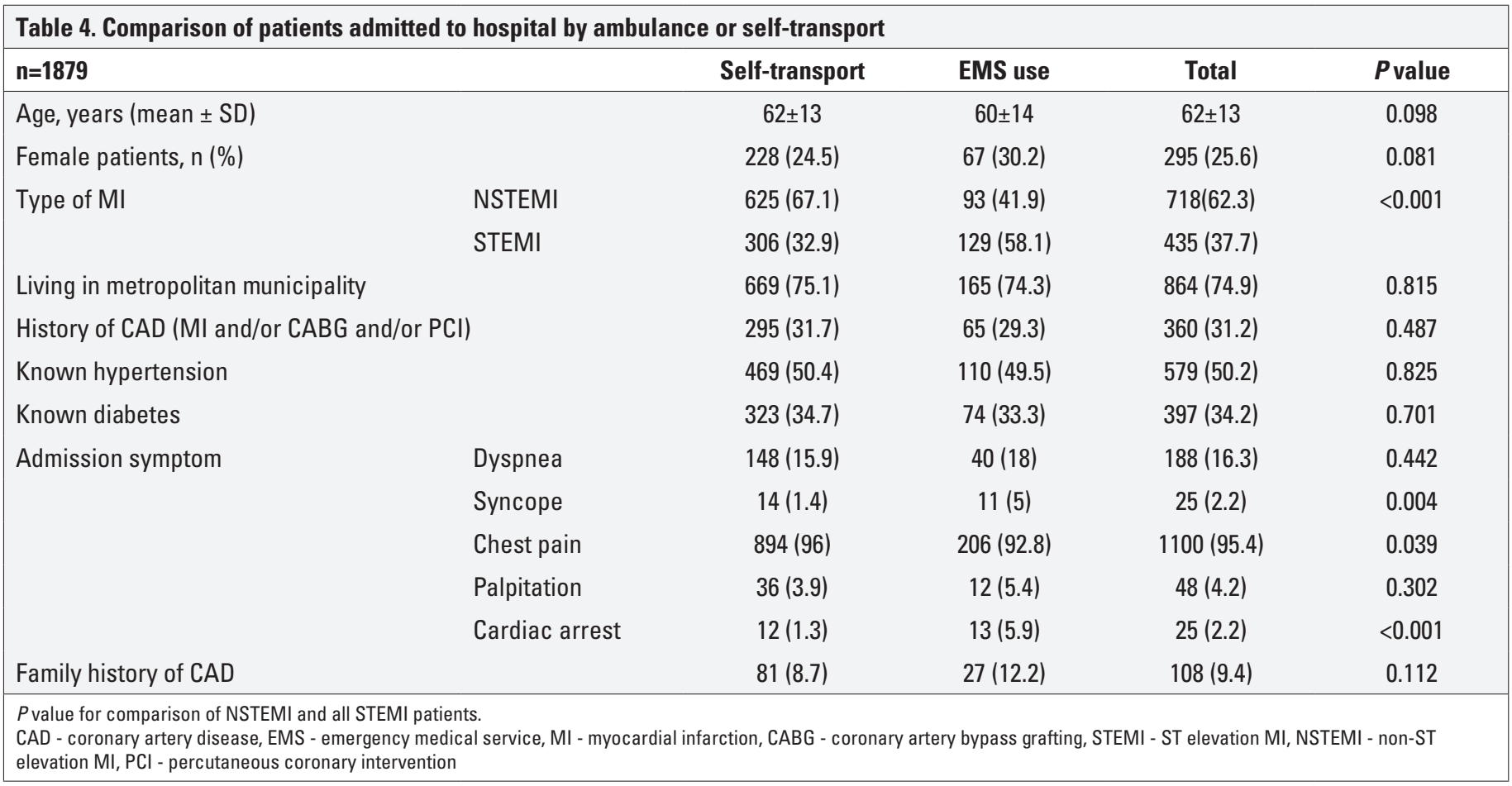

Table 5. Factors associated with time delay in patients with STelevation myocardial infraction (data for age given in Fig. 1)

\begin{tabular}{|lcc|}
\hline & $\begin{array}{c}\text { Percent change in total } \\
\text { ischemic time, Mean (95\% CI) }\end{array}$ & $\boldsymbol{P}$ value \\
\hline Male & $0.59(-6.73$ to 8.49$)$ & 0.875 \\
History of CAD & $-8.48(-17.09$ to 1.03) & 0.077 \\
History of hypertension & $1.36(-6.18$ to 9.49) & 0.725 \\
History of diabetes & $4.67(-3.03$ to 12.99) & 0.233 \\
Family History of CAD & $-5.52(-13.33$ to 2.99$)$ & 0.190 \\
Arrival (reference EMS call) & & \\
Transported from other & 23.27 (15.24 to 31.86) & $<0.001$ \\
hospital & & \\
Self-transport & 5.40 (-0.54 to 11.69) & 0.074 \\
\hline $\begin{array}{l}\text { Negative values correspond to lower total ischemic time. } \\
\text { CAD - coronary artery disease, EMS - emergency medical service }\end{array}$ \\
\hline
\end{tabular}

without $\mathrm{PCl}$ capability to a hospital with $\mathrm{PCl}$ capability had $23.3 \%$ higher TIT than those who were brought directly to a $\mathrm{PCI}$ capable hospital by EMS ambulance $(p<0.001)$. In addition, patients who arrived at a $\mathrm{PCl}$-capable hospital using self-transport (without calling EMS) had $5.4 \%$ increase in TIT than those who were brought to these hospitals by EMS ambulance $(p=0.074)$.

In patients with NSTEMI, age was not a significant predictor of time delay ( $p=0.280$ for linear relationship, Table 6 ). Although a shallow, U-shaped relationship was observed in Figure 1 (lower panel), the nonlinear relationship was not significant ( $p=0.547)$. In patients with NSTEMI, the only significant factor associated with time delay was the mode of hospital arrival (Table 6).
Table 6. Factors associated with time delay in patients with Non-ST elevation myocardial infarction

\begin{tabular}{|lcc|}
\hline & $\begin{array}{c}\text { Percent change in time } \\
\text { delay, Mean (95\% CI) }\end{array}$ & $\boldsymbol{P}$ value \\
\hline Age & $0.15(-0.13$ to 0.42) & 0.280 \\
Male & $0.10(-5.9$ to 6.49) & 0.973 \\
History of CAD & $0.85(-5.28$ to 7.37) & 0.785 \\
History of hypertension & $1.77(-4.14$ to 8.04) & 0.555 \\
History of diabetes & $1.48(-3.77$ to 7.02) & 0.577 \\
Family History of CAD & $-2.40(-10.02$ to 5.86) & 0.547 \\
Arrival (reference EMS call) & & \\
Transported from other & $60.03(43.16-78.9)$ & $<0.001$ \\
hospital & $12.05(-0.41$ to 26.08) & 0.058 \\
$\begin{array}{l}\text { Self-transport } \\
\text { Risk category (ref: low- } \\
\text { moderate risk) } \\
\text { High-very high risk }\end{array}$ & \\
\hline $\begin{array}{l}\text { Negative values correspond to earlier presentation. } \\
\text { CAD - coronary artery disease, EMS - emergency medical service }\end{array}$ & \\
\hline
\end{tabular}

Patients who were transferred from another hospital to the study center (PCl-capable center) had a $60 \%$ delay $(p<0.001)$, and those who self-transported had a $12 \%$ delay $(p=0.058)$ on arrival at the PCl-capable center than those brought by ambulance. Patients with high or very high-risk characteristics had $6.6 \%$, but not significant, earlier presentation than those with moderate or low-risk characteristics ( $p=0.251)$.

When all the patients with STEMI and NSTEMI were combined and adjusted for age; sex; history of CAD, hypertension, 

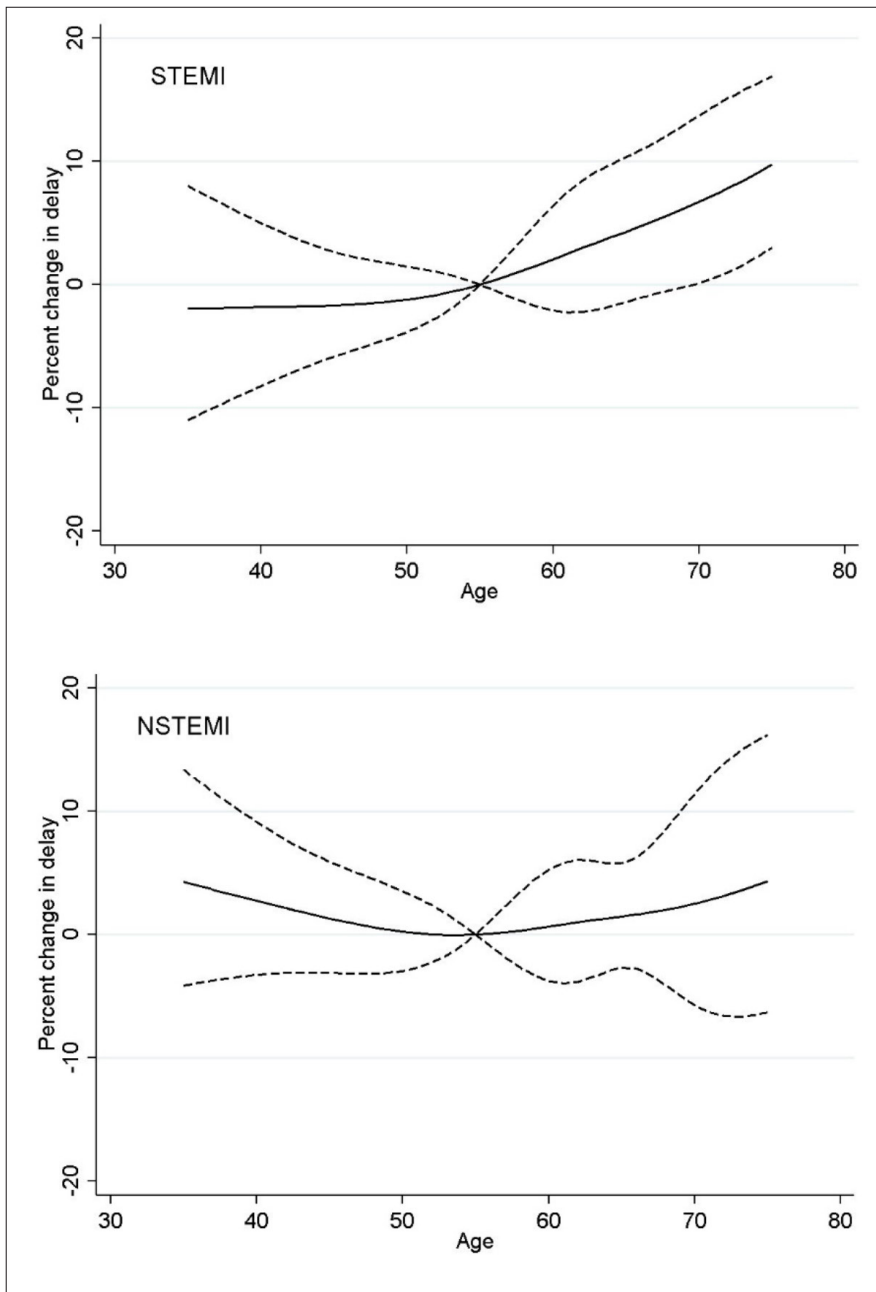

Figure 1. Age dependent percent change in time delay in STEMI (upper panel) and NSTEMI (lower panel). Solid line corresponds to mean values and dashed lines correspond to its $95 \%$ confidence interval. Age of 55 years was used as reference point. Negative values denote earlier hospital arrival in NSTEMI and lower total ischemic time in STEMI STEMI - ST-segment elevation myocardial infarction, NSTEMI- Non-ST-segment myocardial infarction

and diabetes; family history of CAD; and arrival type, patients with STEMI had a $37.3 \%$ earlier presentation to the hospital than those with NSTEMI $(-37.3 \%$, 95\% confidence interval $--43.4 \%$ and $-30.6 \% ; p<0.001$ ) as expected.

\section{Discussion}

The baseline evaluation of the TURKMI study revealed that an important proportion of patients presenting with AMI within the 48 hours of symptom onset get PCl treatment later than the time proposed in the guidelines, and the use of EMS for admission is extremely low in Turkey.

The time from the onset of symptoms to the EMS call was almost one hour for NSTEMI and half an hour for STEMI in the TURKMI population. As this period completely depends on the patient's ability to realize the severity of the problem, it is obvious that this long time gap can only be reduced by increasing public awareness of early recognition of the signs and symptoms of AMI.

Another important finding that should be interpreted was the low rate of ambulance use in the TURKMI study. Almost half the patients were admitted to the study centers by self-transport, whereas only a small proportion (11.8\%) called EMS. The low use of EMS may be the probable explanation of the overall $37.6 \%$ transfer rate from non-PCl-capable centers resulting in a median of $172.5 \mathrm{~min}$ in inter-hospital transport. This median time loss during inter-hospital transport was $120 \mathrm{~min}$ in patients with STEMI, which covers the golden hours of revascularization. The advantages of EMS use in reducing mortality have been well addressed. Besides providing rapid availability of advanced cardiac life support personnel for out-of-hospital cardiac arrest, EMS transports patients directly to the 24/7 PCl capable centers and potentially shortens the time to reperfusion therapy (9). Our results also revealed that the median time gap between the EMS call to EMS arrival at the patients' place was only $15 \mathrm{~min}$. Ambulance use was also lower in 2 previous Turkish registries, $43 \%$ in the TUMAR study and $42 \%$ in the TURK-AKS, but not as low as in TURKMI $(10,11)$. TUMAR study had enrolled patients with AMI within 24 hours of symptom onset in 1998 and 1999 (10). Though not mentioned in the article, in the TURK-AKS registry, the mean time from symptom to hospital arrival was $130 \mathrm{~min}$, probably denoting the enrollment of patients with an earlier presentation after the onset of symptoms (11). As both registries enrolled patients nonconsecutively, selection bias could be another explanation of the difference in EMS use. The frequency of ambulance use has a wide range in different countries. According to the registries, $78.9 \%$ of Japanese prefer to call EMS, whereas only $5 \%$ of patients with $\mathrm{MI}$ are admitted to cardiac centers by EMS ambulance in Saudi Arabia $(12,13)$. However, these results are not comparable as the registries have different exclusion and inclusion criteria and designs.

In our study population, more patients preferred self-transportation to the hospital instead of calling EMS. Moreover, age; sex; history of CAD, diabetes, or hypertension; and family history of CAD were similar between the patients who used an ambulance and those who were self-transported. Only the kind of symptom and type of MI were different between the groups. Of note, we did not assess the effect of education level on the transport type owing to a very high number of missing values. It is clear that the very low rate of EMS use denotes low awareness among patients on the advantages of EMS use and also probably the signs and risks of MI. Meischke et al. (14) have reported that EMS is underused because patients think that selftransport would be faster, or because they do not perceive their symptoms as being life-threatening. Therefore, our results highlight the need for an awareness campaign (public education) on both the signs of $\mathrm{MI}$ and also the importance of early arrival at the hospital for early revascularization, which could be afforded faster and safer by EMS. Public education should cover the importance of time for myocardial salvage and EMS as the best option of faster and safer transfer directly to the 24/7 PCl capable centers. 
The evaluation of time gaps in TURKMI revealed that the D2B time with a median of 36.5 min was quite reasonable for patients with STEMI. However, the overall TIT of 195 min we observed in the TURKMI registry was considerably longer than proposed in the guidelines (1). Moreover, the TIT was 100 min longer if the patients were transferred from another hospital. The recommended timing of less than 120 min for TIT was achieved only in $38 \%$ of patients admitted directly to primary $\mathrm{PCl}$ hospitals and in $13 \%$ of those referred from a hospital without PCI capability. Regression analysis also revealed that the of arrival at the study centers was the most important factor in determining the duration of TIT, emphasizing again the need for public awareness of the importance of EMS call in case of AMI. Both D2B time and TIT show a large variability between the registries of different countries. For example, D2B time was reported to be $60 \mathrm{~min}$ in the Korean Registry 2018 data and 41 min in the UK-MINAP 2019 report (15). TIT was $120 \mathrm{~min}$ in the UK-MINAP data and $189 \mathrm{~min}$ in the Korean Registry (16). Again, the inclusion-exclusion criteria of the individual registries might have affected the observed wide range both in D2B time and TIT.

Another important finding of the TURKMI registry was the fact that despite the median delay for transfer between hospitals for patients who were transferred for $\mathrm{PCl}$ being $120 \mathrm{~min}$, the use fibrinolytic therapy was very low in these patients. However, current guidelines recommend fibrinolytic therapy for those patients who cannot be treated with primary $\mathrm{PCI}$ within $120 \mathrm{~min}$ of symptom onset. This finding signifies the need for measures, including the co-organization of EMS and hospitals to shorten TIT according to current guidelines.

TURKMI data revealed that an important proportion of patients with NSTEMI are not managed according to the riskbased approach as recommended in the current guidelines. Coronary angiograms were obtained within the first 2 hours of symptom onset in only $24.1 \%$ of the very high-risk patients and within the first 24 hours in $64.7 \%$ of those with high-risk. However, it is well known that a risk-based treatment algorithm in NSTEMI improves outcomes (2). Therefore, precautions are warranted to increase the awareness of cardiologists with regard to the importance of the risk-based approach in patients presenting with NSTEMI. Herein, we may also suggest that patients with NSTEMI and probably not severe symptoms preferred self-transport to hospitals leading to increased admissions to centers without $\mathrm{PCI}$ capability, which in turn prolonged the time to revascularization with additional extra transfer time to PCl-capable hospitals.

\section{Study limitations}

As in all MI registries, this study has inherent limitations of registries, as well. Lack of data about the distance each patient lived from the study centers might be accepted as a limitation; however, to take into account the effect of location, cities were used as a cluster variable, and clustered, robust standard errors were calculated in the regression analyses. TURKMI also aimed to evaluate only patients with $\mathrm{AMI}$ who were admitted to $\mathrm{PCl}$ - capable centers and did not include those who died at home, during transportation, or in the emergency services. Another limitation of this study was that education level was not assessed in the statistical analyses because of the high number of missing values. In addition, the type of transfer to the first hospital was not taken into consideration in patients who were transferred from one hospital to another hospital with $\mathrm{PCI}$ capability.

\section{Conclusion}

The baseline analysis of time gaps of TURKMI revealed important information about where the management of $\mathrm{AMI}$ needs further efforts to improve the care of AMI in Turkey. Accordingly, patient-related factors, that is, underuse of EMS and longer time from symptom to EMS call seem to be the major factors leading to the prolonged duration of ischemia (time to treatment) during the course of AMI. Furthermore, the low rate of risk-based approach in patients with NSTEMI and the low use of fibrinolytic therapy in patients with STEMI who were transferred from non- $\mathrm{PCl}$ capable centers, despite a median delay of 120 min between the hospitals, were other important points to focus on to improve the prognosis. As TURKMI represents the first nationwide registry of consecutively enrolled AMI patients, these observations should be accepted as a call to action to improve AMI care in Turkey. Effective community and patient education is necessary to resolve patient related delays to treatment and increase the use of EMS. Further education of physicians and establishing an effective, rapid communication system between the hospitals that enables the initiation of therapies during transport could also help in affording earlier coronary patency, better patient stabilization, and improved survival.

Acknowledgments: Statistical analyses were conducted by Omega CRO, Ankara, Turkey. The electronic case report form and the data capture program (OpenClinica LLC and collaborators, Waltham, MA, USA) hosted were by Omega CRO, Ankara, Turkey. TURKMI registries are investigator-initiated trials and sponsored by the Turkish Society of Cardiology, which received major, unrestricted funding from AstraZeneca for this project. The funder had no role in study design, data collection, data analysis, data interpretation, or writing of the report.

Conflict of interest: All the authors report nonfinancial support from AstraZeneca during the conduct of the study.

Peer-review: Externally peer-reviewed.

Data sharing: The presented data is accessible to researchers upon reasonable request to the first 3 authors (MKE, MKa, and MKi) for data sharing.

Author contributions: Concept - M.K.E., M.Kayıkçıoğlu, M. Kılıçkap; Design - M.K.E., M.Kayıkçıoğlu, M.Kılıçkap; Supervision M.K.E., M.Kayıkçıoğlu, M.Kılıçkap; Fundings - M.K.E., M.Kayıkçıoğlu, M.Kılıçkap; Materials - M.K.E., M.Kayıkçıoğlu, M.Kılıçkap; Data collection \&/or processing - M.K.E., M.Kayıkçıoğlu, M.Kılıçkap; Analysis 
\&/or interpretation - M.K.E., M.Kayıkçıoğlu, M.Kılıçkap, A.G., Ö.Öztürk, B.T., S.I., I.B., F.P.T., Ö.F.Ç., E.G., E.M.B., Ç.Y., M.A.A., B.D.K., E.A., Y.A., N.E., M.K.T., N.T.Ç., R.D., M.I., Ö.Özdoğan, O.Y.; Literature search M.K.E., M.Kayıkçıoğlu, M.Kılıçkap, A.G., Ö.Öztürk, B.T., S.I., I.B., F.P.T., Ö.F.Ç., E.G., E.M.B., Ç.Y., M.A.A., B.D.K., E.A., Y.A., N.E., M.K.T., N.T.Ç., R.D., M.I., Ö.Özdoğan, O.Y.; Writing - M.K.E., M.Kayıkçığlu, M. Kılıçkap, A.G., Ö.Öztürk, B.T., S.I.,, I.B., F.P.T., Ö.F.Ç., E.G., E.M.B., Ç.Y., M.A.A., B.D.K., E.A., Y.A., N.E., M.K.T., N.T.Ç., R.D., M.I., Ö.Özdoğan, O.Y.; Critical review - M.K.E., M.Kayıkçıoğlu, M.Kılıçkap, A.G., Ö.Öztürk, B.T., S.I., I.B., F.P.T., Ö.F.Ç., E.G., E.M.B., Ç.Y., M.A.A., B.D.K., E.A., Y.A., N.E., M.K.T., N.T.Ç., R.D., M.I., Ö.Özdoğan, O.Y.

\section{TURKMI Study Group:}

Abant Izzet Baysal University: Mehmet Inanir, Osman Yasin Yalçin, Yilmaz Gunes; Adana City Hospital: Ibrahim Halil Kurt, Omer Genc, Abdullah Yildirim; Adiyaman University: Ramazan Asoglu; Aksaray University: Sinan Inci; Ankara NumuneTraining and Research Hospital: Ender Ornek, Mustafa Cetin, Emrullah Kiziltunc; Ankara University: Mustafa Kilickap; Ankara Yuksek Ihtisas Training and Research Hospital: Cagrı Yayla, Ahmet Goktuğ Ertem, Mehmet Kadri Akboga; Antalya Training and Research Hospital: Ahmet Genc, Gulsum Meral Yılmaz Oztekin; Batman State Hospital: Mesut Gitmez; Bursa Yuksek Ihtisas Training and Research Hospital; Burcu Tuncay, Veysi Can, Hasan Ari; Bulent Ecevit University: Fatih Pasa Tatar, Mustafa Umut Somuncu; Canakkale Onsekiz Mart University; Emine Gazi; Cukurova University; Cuma Yeşildas, Onur Sinan Deveci; Denizli State Hospital: Okan Er; Diyarbakir Gazi Yasargil Training and Research Hospital: Onder Ozturk; Ege University: Aytac Candemir, Meral Kayikçioglu, Oguz Yavuzgil; Elazıg Training and Research Hospital: Cetin Mirzaoğlu; Erzincan Binali Yildirim University: Eftal Murat Bakirci, Husnu Degirmenci; Harran University: Feyzullah Besli; Istanbul Bagcılar Training and Research Hospital: Orhan Ince, Emirhan Hancıoglu; Istanbul Bakirkoy Sadi Konuk Training and Research Hospital: Ibrahim Faruk Akurk, Ersan Oflar, Nihan Turhan Çaglar; Istanbul Bezmi Alem University: Hatice Aylin Yamac Halac; Istanbul Haseki Training and Research Hospital: Muhsin Kalyoncuoglu; Istanbul Kartal Kosuyolu Training and Research Hospital: Ismail Balaban, Mesut Karatas, Cevat Kirma; Istanbul Mehmet Akif Ersoy Training and Research Hospital: Arda Guler, Cemil Can, Arda Can Dogan, Ahmet Arif Yalcin; Istanbul International Sisli Kolan Hospital: Mustafa Kemal Erol; Istanbul Siyami Ersek Training and Research Hospital: Can Baba Arin; Istanbul University Cardiology Institute; Umit Yasar Sinan; Izmir Tepecik Training and Research Hospital: Murat Kücükokur, Oner Ozdogan; Kahramanmaras Sutcu Imam University: Ekrem Aksu, Hakan Günes; Kayseri Training and Research Hospital: Ziya Simsek, Eyüp Ozkan; Kırıkkale Yuksek Ihtisas Training and Research Hospital: Cengiz Sabanoğlu, Yunus Celik; Kutahya Dumlupinar University: Taner Sen, Mehmet Ali Astarcıoglu; Malatya Training and Research Hospital: Ibrahim Aktas, Gokhan Gozubuyuk; Marmara University: Mustafa Kursat Tigen, Murat Sunbul; Mersin University: Ayça Arslan, Ahmet Celik; Mustafa Kemal University: Oguz Akkus; Necmettin Erbakan University: Yakup Alsancak; Osmangazi University: Muhammet Dural, Kadir Ugur Mert; Mugla Yucelen Hospital: Nuri Kose; Pamukkale University: Ismail Dogu Kiliç; Recep Tayyip Erdogan University: Nadir Emlek; Sakarya University: Ibrahim Kocayigit; Samsun Training and Research Hospital: Ahmet Yanik, Mustafa Yenerçag; Trabzon Ahi Evran Training and Research Hospital: Omer Faruk Çitrakoglu, Ihsan Dursun; Trakya University: Utku Zeybey, Servet Altay; Urfa Mehmet Akif Inan Training and Research Hospital: Sadettin Selcuk Baysal; Van Training and Research Hospital: Nesim Aladag, Remzi Sarikaya, Ramazan Duz; Van
Yuzuncu Yil University: Mustafa Tuncer, Hasim Tuner; Yalova State Hospital: Ismail Ungan, Yildirim Beyazit University: Bilge Duran Karaduman, Engin Bozkurt.

\section{References}

1. Ibanez B, James S, Agewall S, Antunes MJ, Bucciarelli-Ducci C, Bueno H, et al.; ESC Scientific Document Group. 2017 ESC Guidelines for the management of acute myocardial infarction in patients presenting with ST-segment elevation: The Task Force for the management of acute myocardial infarction in patients presenting with ST-segment elevation of the European Society of Cardiology (ESC). Eur Heart J 2018; 39: 119-77. [Crossref]

2. Roffi M, Patrono C, Collet JP, Mueller C, Valgimigli M, Andreotti F, et al.; ESC Scientific Document Group. 2015 ESC Guidelines for the management of acute coronary syndromes in patients presenting without persistent ST-segment elevation: Task Force for the Management of Acute Coronary Syndromes in Patients Presenting without Persistent ST-Segment Elevation of the European Society of Cardiology (ESC). Eur Heart J 2016; 37: 267-315. [Crossref]

3. Doddipalli SR, Rajasekhar D, Vanajakshamma V, Sreedhar Naik K. Determinants of total ischemic time in primary percutaneous coronary interventions: A prospective analysis. Indian Heart J 2018; 70 Suppl 3: S275-9. [Crossref]

4. Cubeddu RJ, Palacios IF, Blankenship JC, Horvath SA, Xu K, Kovacic JC, et al. Outcome of patients with ST-segment elevation myocardial infarction undergoing primary percutaneous coronary intervention during on- versus off-hours (a Harmonizing Outcomes with Revascularization and Stents in Acute Myocardial Infarction [HORIZONS-AMI] trial substudy). Am J Cardiol 2013; 111: 946-54. [Crossref]

5. Erol MK, Kayıkçıoğlu M, Kılıçkap M. Rationale and design of the Turkish acute myocardial infarction registry: The TURKMI Study. Anatol J Cardiol 2020; 23: 169-75. [Crossref]

6. Erol MK, Kayıkçıoğlu M, Kılıçkap M, Arın CB, Kurt IH, Aktaş I, et al. Baseline clinical characteristics and patient profile of the TURKMI registry: Results of a nation-wide acute myocardial infarction registry in Turkey. Anatol J Cardiol 2020; 24: 43-53. [Crossref]

7. Wikipedia contributors. NUTS statistical regions of Turkey. Wikipedia, The Free Encyclopedia; 2019 Apr 14, 20:24 UTC [cited 2019 Aug 16] (accessed Jan 2020). [Internet]. Available from: URL; https://en.wikipedia.org/w/index.php?title=NUTS_statistical_ regions_of_Turkey\&oldid=892478048.

8. Thygesen K, Alpert JS, Jaffe AS, Simoons ML, Chaitman BR, White HD, et al.; Writing Group on the Joint ESC/ACCF/AHA/WHF Task Force for the Universal Definition of Myocardial Infarction. Third universal definition of myocardial infarction. Eur Heart J 2012; 33 : 2551-67. [Crossref]

9. Canto JG, Zalenski RJ, Ornato JP, Rogers WJ, Kiefe Cl, Magid D, et al.; National Registry of Myocardial Infarction 2 Investigators. Use of emergency medical services in acute myocardial infarction and subsequent quality of care: observations from the National Registry of Myocardial Infarction 2. Circulation 2002; 106: 3018-23. [Crossref]

10. Enar R. Acute myocardial infarction Thrombocardiology [Turkish] 2nd ed. İstanbul: Nobel Tıp Kitabevi; 2004.

11. Kozan 0, Ergene 0, Oto A, Kaplan K; TURK-AKS Investigators. A real life registry to evaluate patient profile, diagnostic and practice patterns in Acute Coronary Syndrome in Turkey: TURK-AKS study. Int J Cardiovascular Academy 2017; 3: 85-93. [Crossref] 
12. Kojima S, Nishihira K, Takegami M, Nakao YM, Honda S, Takahashi $J$, et al.; JAMIR Investigators. Nationwide real-world database of 20,462 patients enrolled in the Japanese Acute Myocardial Infarction Registry (JAMIR): Impact of emergency coronary intervention in a super-aging population. Int J Cardiol Heart Vasc 2018; 20: 1-6. [Crossref]

13. Alhabib KF, Kinsara AJ, Alghamdi S, Al-Murayeh M, Hussein GA, AlSaif $S$, et al. The first survey of the Saudi Acute Myocardial Infarction Registry Program: Main results and long-term outcomes (STARS-1 Program). PLoS One 2019; 14: e0216551. [Crossref]
14. Meischke H, Ho MT, Eisenberg MS, Schaeffer SM, Larsen MP. Reasons patients with chest pain delay or do not call 911. Ann Emerg Med 1995; 25: 193-7. [Crossref]

15. Kim I, Kim MC, Park KH, Sim DS, Hong YJ, Kim JH, et al. Prognostic significance of non-chest pain symptoms in patients with non-STsegment elevation myocardial infarction. Korean J Intern Med 2018; 33: 1111-8. [Crossref]

16. Wilkinson C, Weston C, Timmis A, Quinn T, Keys A, Gale CP. The Myocardial Ischaemia National Audit Project (MINAP). Eur Heart J Qual Care Clin Outcomes 2020; 6: 19-22. [Crossref] 